\title{
Thermodynamical aspects of the passage to hybrid nuclear power plants
}

\author{
A. Zaryankin, A. Rogalev \& I. Komarov \\ Moscow Power Engineering Institute, Russia
}

\begin{abstract}
This paper deals with a method of efficiency and power capacity for nuclear power plants, with the increase of pressurized water reactors at the expense of the passage to hybrid technologies. The essence of such a passage lies within two types of fuel applications and is realized by outer (in the case of a nuclear steam generating unit) steam superheater usage, which consumes fossil or hydrogen fuel.
\end{abstract}

Keywords: hybrid nuclear power plant (NPP), outer steam superheater, hydrogen steam superheater, super powerful steam turbine.

\section{Introduction}

When considering the challenge of increasing the efficiency of power units particular attention should be given to nuclear power plants (NPP), as their efficiency does not exceed 33-34\%.

This situation can be changed and the efficiency of electricity generation at nuclear power plants could be increased to match the efficiency level of a thermal power plant, but only if reliable industrial nuclear reactors are created, which can generate super heated steam at temperatures between 500 and $700^{\circ} \mathrm{C}$.

Unfortunately such industrial reactors are only produced in single copies and their application means the passage to a new type of nuclear power plant. It is obvious that this route requires a lot more time and has higher material costs.

The alternative method for NPP electrical efficiency and increase in power capacity is outer steam super heating, generated by fossil or hydrogen fuel, which is the passage to hybrid power units. Such a route allows for the equipment of the reactor block to remain the same, whilst installing an outer (relative to reactor steam generator) steam superheater and a new super powerful high temperature steam turbine. 
The following materials are considered as alternative measures for NPP turbo installation thermal schemes with the application of fossil and hydrogen fuel for stem superheating.

\section{Characteristics of the base turbo installation}

For further investigation, using an initial thermal diagram of turbo installation, a steam turbine K-1000-60/3000 was chosen. The thermal diagram of this turbo installation is shown in fig. 1.

Saturated steam at pressure $p_{0}=5.89 \mathrm{MPa}$ enters into a double-flow high pressure cylinder (HPC) where it expands. The steam pressure and the humidity behind the HPC are equal to $0.58 \mathrm{MPa}$ and $14.4 \%$ respectively. In these conditions steam goes through four separator-superheaters (SS), where moisture is separated and steam is superheated by a live steam flow of up to $250^{\circ} \mathrm{C}$. Steam pressure behind the SS is $0.51 \mathrm{MPa}$ after the SS steam enters into the four double flow low pressure cylinders (LPC). Cylinders are integrated by pairs in two groups; $1-2$ and 3-4. Behind each group the steam enters two condensers where cooling water serially runs through their tubes. Because of such a connecting diagram of pressure, the pressure in the first condenser is equal to $4.3 \mathrm{k} \mathrm{Pa}$ but in the second one it is equal to $5.5 \mathrm{k} \mathrm{Pa}$.

After the condensate is pumped by the condensate pumps at the first stage through the condensate purification plant and low pressure heater 1 (LPH 1), it enters into direct contact with the low pressure heater 2 (LPH 2). It then experiences further pumping through LPH 3, 4, and 5 and a deaerator is activated at the condensate pumps of the second stage.

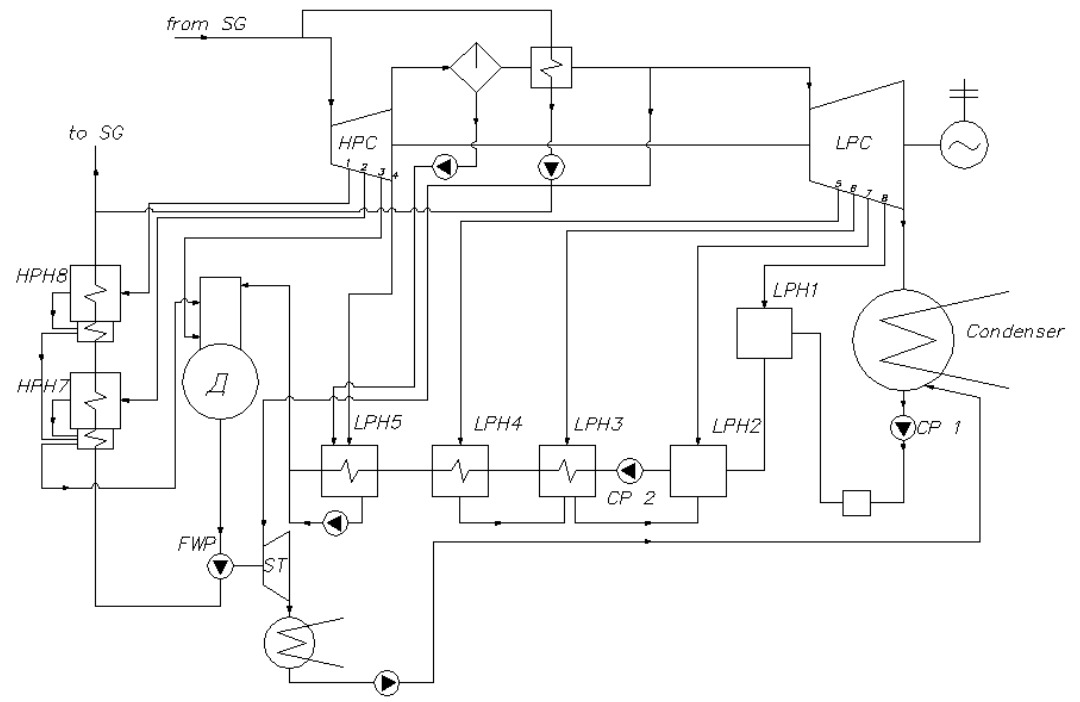

Figure 1: Conventional nuclear power plant turbo installation thermal diagram. 
After the deaerator's water feed is pumped through two feed pumps with a steam turbine drive and through HPH 6 and 7 it enters the steam generator of the nuclear steam-generating plant.

In the process of the thermal diagram calculation it should be accounted for that the condensate from the separator enters into LPH 5 and from the condensate of the heating steam to the steam from the superheater is pumped through to feed the water line before the steam generator. [1].

The primary characteristics of the base turbo installation are shown in table 1

Let us consider how these characteristics change in different cases of outer superheater application.

Table 1: Primary characteristics of base turbo installation.

\begin{tabular}{|l|c|}
\hline \multicolumn{1}{|c|}{ Characteristics } & Value \\
\hline Electric power $N e, \mathrm{MW}$ & 1000 \\
\hline Live steam mass flow $G_{0}, \mathrm{~kg} / \mathrm{s}$ & 1630.5 \\
\hline Average pressure in the condenser $p c, \mathrm{kPa}$ & 4.9 \\
\hline Feed water temperature $t_{f w},{ }^{\circ} \mathrm{C}$ & 220 \\
\hline HPC internal relative efficiency $\eta_{o i}{ }^{H P C}$ & 0.83 \\
\hline LPC internal relative efficiency $\eta_{o i}{ }^{L P C}$ & 0.82 \\
\hline Heat rate $q, \mathrm{~kJ} /\left(\mathrm{kW}^{*} \mathrm{~h}\right)$ & 10387 \\
\hline Turbo installation electrical efficiency $\eta_{\ni}$ & 0.3466 \\
\hline
\end{tabular}

\section{Turbo installation with outer steam superheating}

The outer (relative to a nuclear reactor) steam superheating system can be realized at the expense of the combustion heat of fossil or hydrogen fuel.

The simplest method of outer steam superheating in terms of practical realization is by opting for a scheme that uses a fossil fuel fired boilersuperheater with single superheating of the live steam. The estimation that has been carried out shows that we can exclude the moisture separator-superheater from the NPP process flow sheet when the initial steam temperature reaches a defined level. The live steam temperature level is defined by the humidity of a low pressure cylinder at the last stage. The required temperature can be determined by a chart (fig. 2) where the dependence between steam humidity after the last stage and the initial steam temperature is shown. We can see that the minimal temperature, when humidity after the last stage does not exceed an acceptable level $(9 \%)$, is about $600^{\circ} \mathrm{C}$. If the temperature is lower than the specified level of $600^{\circ} \mathrm{C}$ the steam humidity exceeds a permissible limit. This would lead to an increase in the erosion of the low pressure cylinder flow path, especially of the last stage blades. Such a temperature level has already been used in boiler design and the creation of boiler-heaters and, in terms of the application of heat-resistant materials, it is not a problem. 


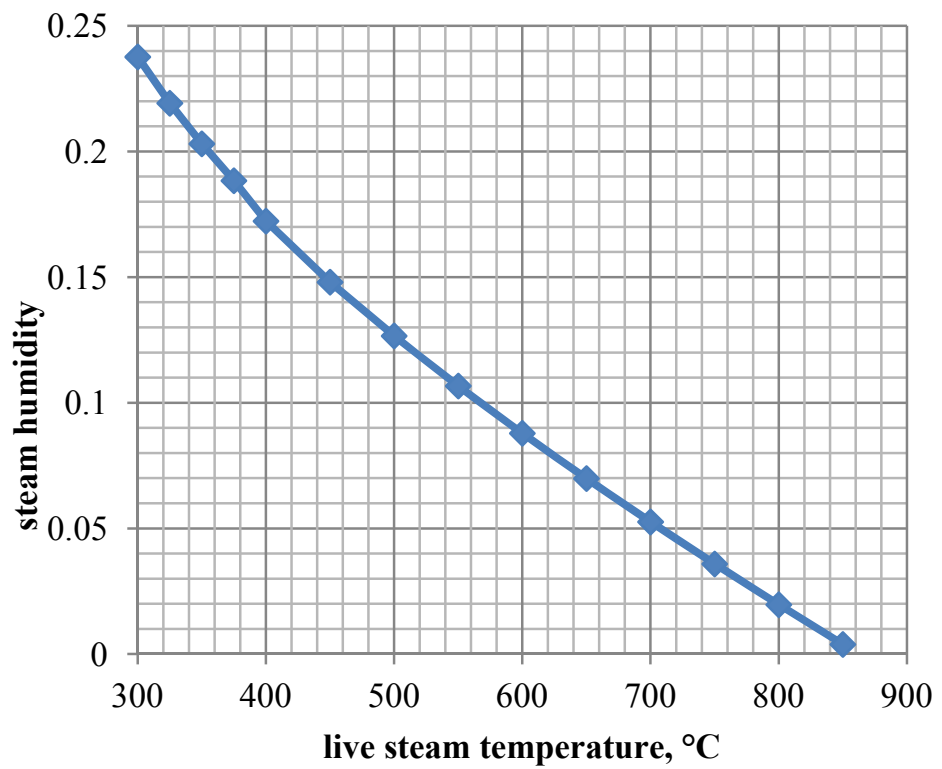

Figure 2: Dependency between humidity after the final turbine stage and the live steam temperature.

The thermal diagram of turbo installation with single steam superheating in the boiler-superheater of up to $600^{\circ} \mathrm{C}$ is illustrated in fig. 3. The main difference from the base turbo installation scheme here consists of the absence of a moisture separator-superheater. All steam flow from the nuclear steam generator goes through the gas-fired boiler-superheater where its temperature increases from $274{ }^{\circ} \mathrm{C}$ to $600^{\circ} \mathrm{C}$ and with this temperature and pressure $5.3 \mathrm{MPa}$ steam enters into a high pressure cylinder. After this, the HPC stem flow instantly goes to the low pressure cylinder and then to the condenser.

Application of this process allows us to increase the NPP power capacity by up to $1,735 \mathrm{MW}$ and reaches an efficiency level of $39.7 \%$. The growth of this power capacity occurs for two reasons. The first reason is the enthalpy growth drop resulting from the temperature rise of live steam. And the second reason is the increase of steam mass flow through the HPC and LPC. Steam mass flow through the HPC rises because of the exclusion process at the steam to steam superheater stage and we don't need to take away any live steam for intermediate superheating, which accounts for about $150 \mathrm{~kg} / \mathrm{s}$ in the base scheme. The mass flow of moisture separation in the moisture separator is also equal to $150 \mathrm{~kg} / \mathrm{s}$. Thus we have a steam mass flow increasing through the HPC by $150 \mathrm{~kg} / \mathrm{s}$ and through the LPC by $300 \mathrm{~kg} / \mathrm{s}$.

A further increment of NPP power capacity and thermal efficiency may be ensured by including a gas-fired boiler-superheater in the turbo installation flow diagram of the intermediate steam superheating. The optimization of intermediate superheating steam conditions was made and as a result we got a set of optimal pressure values for different temperature levels (fig. 4). 


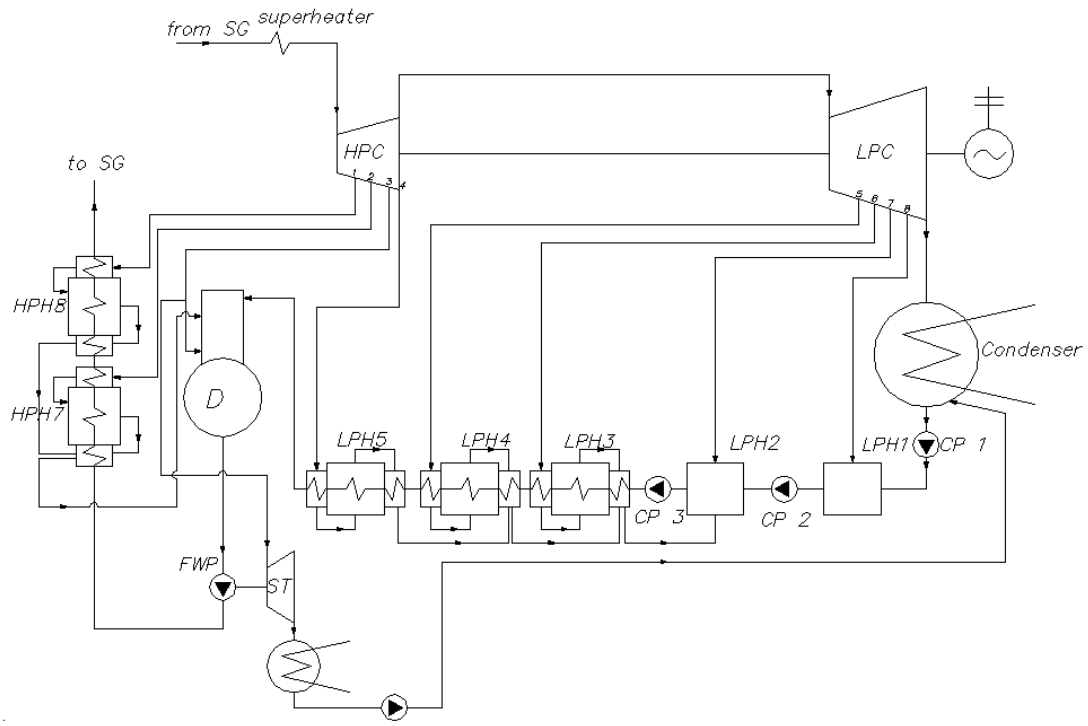

Figure 3: Thermal diagram of NPP turbo installation with steam superheating after the nuclear reactor of up to $t_{0}=600^{\circ} \mathrm{C}$.

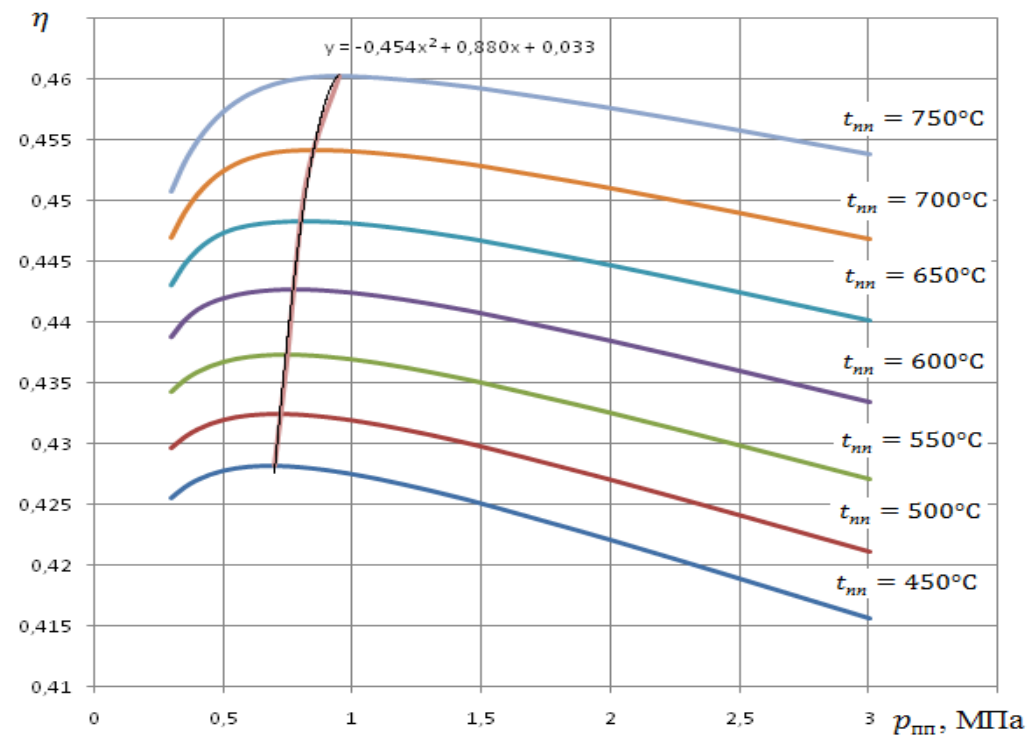

Figure 4: Turbo installation with intermediate steam superheating efficiency as a function of intermediate pressure for different steam temperature levels. 
The function was expected to have an optimal value. For the temperature range from $600^{\circ} \mathrm{C}$ to $650^{\circ} \mathrm{C}$ the optimal intermediate pressure is $0.75-08 \mathrm{MPa}$, but the realization of intermediate superheating at the mentioned pressure leads to heat waste in the condenser because steam at the turbine exhaust will be superheated. Moreover the volume flow of steam will increase sharply and as a result of which we won't realize all the power in one single-shaft turbine.

It should be noted that the efficiency changing in the area of its maximal values is weak. For instance, if the temperature equals $600^{\circ} \mathrm{C}$ the efficiency only changes by $0.15 \%$ in the pressure range from $0.5 \mathrm{M}$ Pa to $1.2 \mathrm{MPa}$. So, we can get dry-saturated steam of steam with a humidity level of $1-2 \%$ at the turbine exhaust stage, at the expense of pressure rising without any considerable efficiency decrease. On the basis of this, the following intermediate pressure and temperature levels were selected: a pressure of $1.2 \mathrm{MPa}$ and a temperature of $620^{\circ} \mathrm{C}$. The expansion process in the steam turbine is shown in fig. 5 .

The thermal diagram of a hybrid NPP with intermediate steam superheating in a gas-fired boiler-superheater is presented in fig. 6. This thermal diagram differs from the previous one only in the presence of an intermediate stem of superheating. The application of such a scheme allows the increase in NPP power capacity for up to $2050 \mathrm{MW}$. The efficiency of turbo installation with intermediate steam superheating reaches $41 \%$.

Outer (relative to nuclear reactor) steam superheating may be realized with the combustion heat of fossil fuel or hydrogen fuel. In the case of hydrogen application for steam superheating the authors of papers [2,3] suggest an increase in temperature in the front of the steam turbine up to $1500^{\circ} \mathrm{C}$. Such

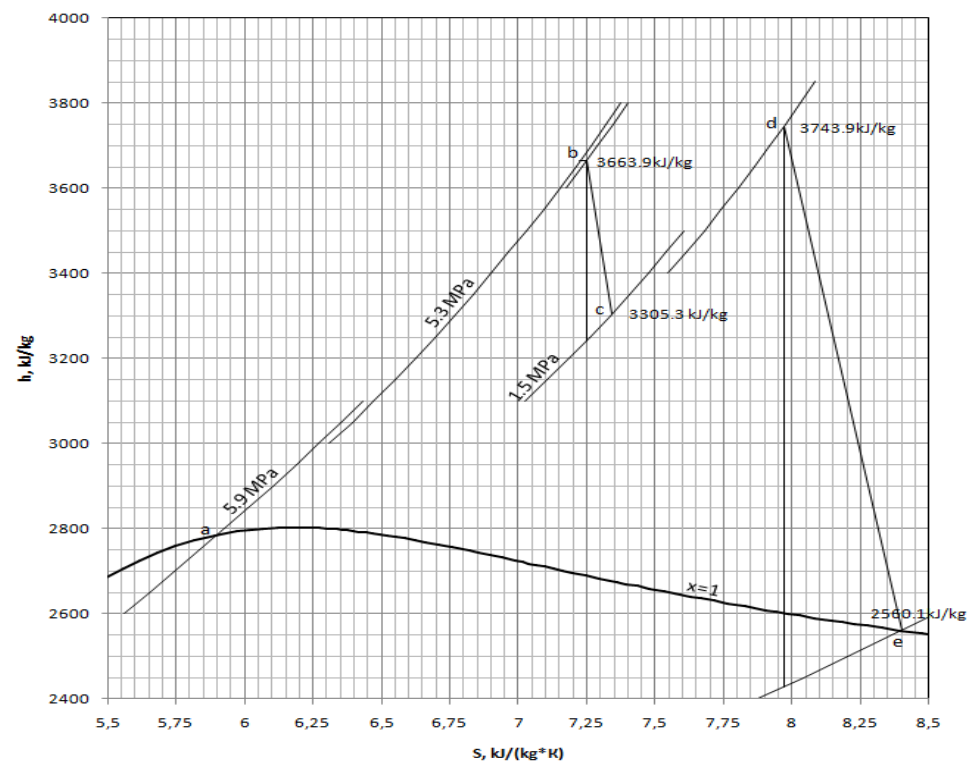

Figure 5: Process of steam expansion in turbine with initial temperature $600^{\circ} \mathrm{C}$ and intermediate superheating temperature $620^{\circ} \mathrm{C}$. 


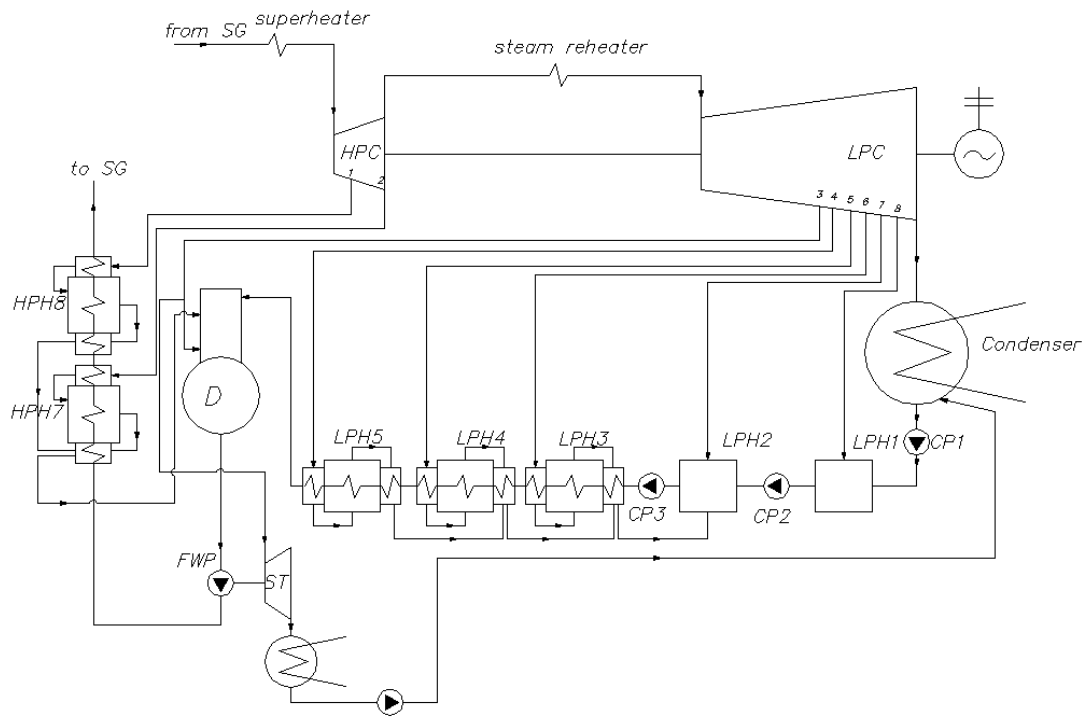

Figure 6: Nuclear power plant turbo installation thermal diagram with initial temperature $600^{\circ} \mathrm{C}$ and intermediate superheating temperature $620^{\circ} \mathrm{C}$.

superheating can be realized by means of using combustion hydrogen fuel with pure oxygen in the special combustion chamber with the further mixing of combustion products (steam) with steam or water in the mixer with cooling steam or water.

In terms of thermodynamics, the increase of steam temperature up to the value indicated above at the constant pressure after the steam generator $\left(p_{0}=6.3 \mathrm{MPa}\right)$ is unreasonable in this case as steam leaves the turbine superheated. This increases the quantity of heat, which transfers to the cooling water. Consequently the superheating energy is irreversibly lost.

This therefore limits the maximum temperature of steam superheating after the steam generator. So, the maximum live steam temperature value selected for the steam behind the final turbine stage stands near the saturation line and steam humidity doesn't exceed $1.5-2 \%$. With such a solution all turbine stages will operate in the superheated steam area and any losses of energy due to moisture in the nuclear power plant turbine losses will be equal to zero. At the same time, in the case of any moisture absence in the turbine flow path, the problem of erosive wear to blading also vanishes.

If, at the internal relative efficiency of the concerned turbo installation, the steam turbine HPC and LPC estimation guide takes into account a greater length of HPC blades the internal relative efficiency of HPC and LPC may be increased to up to $88-90 \%\left(\eta_{o i}{ }^{H P C}=\eta_{o i}{ }^{L P C}=0.88 \div 0.90\right)$. In other words, in the case of the steam superheating after the steam generator rising up to a temperature which would exclude moisture generation in the turbine flow path, the internal relative efficiency of the hybrid nuclear plant turbine can be increased by $6-8 \%$ in 
comparison with the values that are indicated in table 1. For the fulfilment of the aforementioned conditions, the initial temperature of the steam must be equal to $860^{\circ} \mathrm{C}$, where the initial steam pressure is equal to $p_{0}=5.3 \mathrm{MPa}$ and internal relative efficiency of HPC and LPC equals $\eta_{o i}^{H P C}=\eta_{o i}{ }^{L P C}=0.88$.

The energy transformation process in the turbine for the considered case is shown in fig. 7 in $\mathrm{h}-\mathrm{s}$ coordinates.

Point $a$ corresponds to steam conditions behind the steam generator and $a-b$ and $c-d$ lines, to steam expansion in the HPC and LPC of the conventional steam turbine respectively. In the case of outer superheating application with steam superheating of up to $860^{\circ} \mathrm{C}$ the superheating process is shown by the line $a-e$, taking into account the pressure loss. Point $e$ defines the steam conditions in front of the new high-temperature HPC. The line $e-f-g$ describes the expansion of steam in the new turbine.

The thermal diagram of turbo installation under consideration differs from the scheme with single fire superheating (fig. 3 ) in that after the steam generator the steam enters into a hydrogen combustion chamber. In all other things these schemes are the same.

In the process of calculation the main parameters such as live steam mass flow $G_{0}$, pressure in the condenser $p c$, and feed water temperature $t_{f w}$ remain the same. The internal relative efficiency of HPC and LPC was increased up to $\eta_{o i}=$ 0.88 because of the reasons mentioned previously.

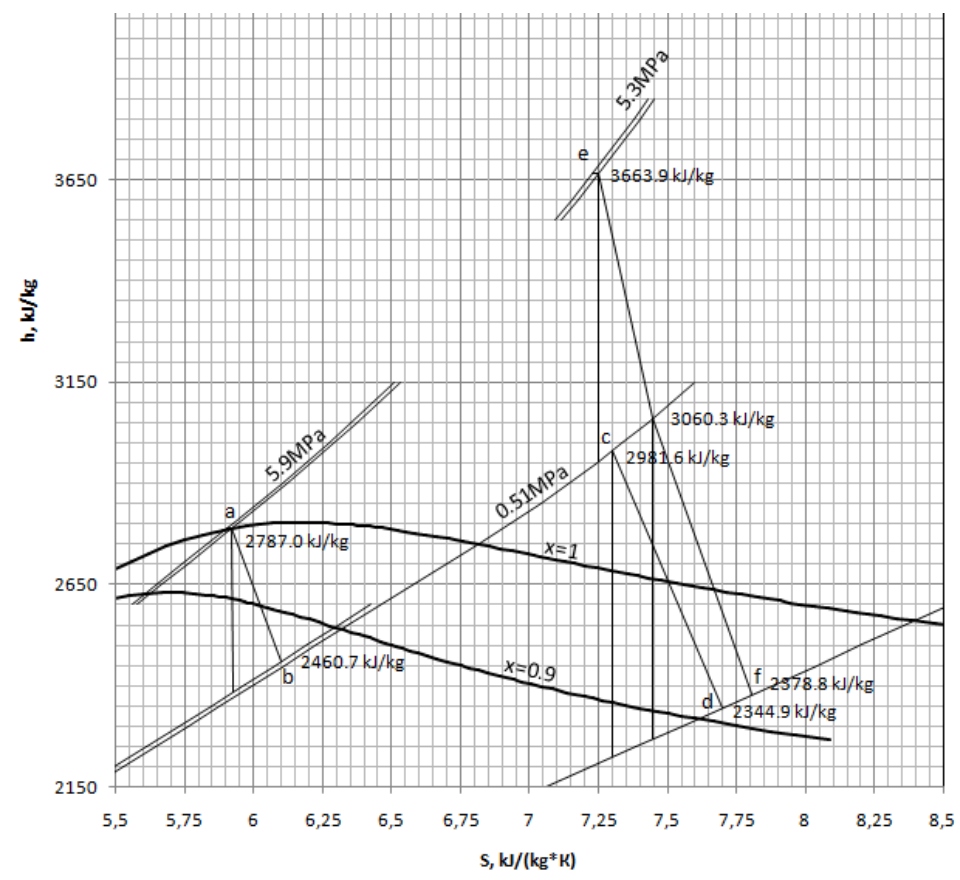

Figure 7: The steam expansion process in the case of steam superheating up to a temperature of $860^{\circ} \mathrm{C}$. 
As a result of these changes in the thermal diagram, the turbo installation power capacity increased by 2.7 times and became $N_{e}=2700 \mathrm{MW}$ and the electrical efficiency of turbo installation reached $52 \%$. In this scheme, as in the scheme with the gas fired superheater, it is the absence of the moisture separator-superheater that leads to the mass flow increase through the steam turbine.

In addition, the steam mass flow rises because of the mix in the main flow of the high temperature steam which is the hydrogen and oxygen combustion product. The additional steam flow which generates as a result of combustion hydrogen with oxygen in the case of steam superheating up to $860^{\circ} \mathrm{C}$ is equal to $196.67 \mathrm{~kg} / \mathrm{s}$. Such a considerable increment of steam mass flow leads to the impossibility for the application of a low pressure cylinder with a last stage blade length of $1200 \mathrm{~mm}$ because of its insufficient throughput capacity. A possible design decision for this problem is the object of independent research. First of all, the comparative analysis of thermal schemes should be provided.

The efficiency of additional power generation is about $65 \%$. The efficiency level that is reached here is considerably higher than similar characteristics of the best combined cycle power plant.

Hydrogen super heating application allows for the avoidance of essential pressure loss in heating surfaces and ensures a higher increment of turbo installation power capacity and thermal efficiency, but it requires a large flow of hydrogen (about $20 \mathrm{~kg} / \mathrm{s}$ ). The decrease of hydrogen consumption may be ensured by the use of a combined scheme of superheating where superheating of up to $600^{\circ} \mathrm{C}$ is realized in a gas-fired boiler and further steam heating of up to $860^{\circ} \mathrm{C}$ occurs in a hydrogen combustion chamber. This scheme ensures the decrease of hydrogen consumption by more than double the original consumption levels, although in this case the increment of power capacity and thermal efficiency decreases a little. Primary characteristics of the scheme with combined superheating are presented in table 2 .

\section{Conclusions}

The research carried out shows that an outer steam superheating application allows for considerable increase in power capacity and thermal efficiency of nuclear power plants with pressurized water reactor WWER-1000. The simplest method of power capacity and thermal efficiency increase is the application of fossil fuel for superheating. In this case the steam superheating of up to $600-620^{\circ} \mathrm{C}$ ensures a power capacity increment under $1050 \mathrm{MW}$, whilst the turbo installation electrical efficiency reaches $41 \%$ and the efficiency of additional power generation is equal to $51 \%$. The prospective method of superheating is superheating in hydrogen combustion. In this way power capacity increases by $1700 \mathrm{MW}$ when the live steam temperature equals $860^{\circ} \mathrm{C}$. The total efficiency of turbo installation is $49 \%$ and the efficiency of additional power production reaches $65 \%$. 
Table 2: General characteristics of hybrid NPP turbo installation.

\begin{tabular}{|c|c|c|c|c|c|c|}
\hline \multirow{4}{*}{ Characteristic } & \multirow{4}{*}{ 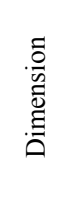 } & \multicolumn{5}{|c|}{ Fuel type } \\
\hline & & - & \multicolumn{2}{|c|}{ fossil fuel } & $\begin{array}{l}\text { hydrogen } \\
\text { fuel }\end{array}$ & $\begin{array}{c}\text { fossil and } \\
\text { hydrogen fuel }\end{array}$ \\
\hline & & \multicolumn{5}{|c|}{ Thermal scheme } \\
\hline & & 1 & 2 & 3 & 4 & 5 \\
\hline $\begin{array}{l}\text { Pressure after steam } \\
\text { generator }\end{array}$ & $\mathrm{MPa}$ & 6.3 & 6.3 & 6.3 & 6.3 & 6.3 \\
\hline $\begin{array}{l}\text { Temperature after steam } \\
\text { generator }\end{array}$ & ${ }^{\circ} \mathrm{C}$ & 274.0 & 274.0 & 274.0 & 274.0 & 274.0 \\
\hline $\begin{array}{l}\text { Steam flow after steam } \\
\text { generator }\end{array}$ & $\mathrm{kg} / \mathrm{s}$ & 1630.5 & 1630.5 & 1630.5 & 1630.5 & 1630.5 \\
\hline Live steam pressure & $\mathrm{MPa}$ & - & 5.35 & 5.35 & 5.67 & 5.32 \\
\hline Live steam temperature & ${ }^{\circ} \mathrm{C}$ & - & 600.0 & 600.0 & 860.0 & 860.0 \\
\hline Live steam mass flow & $\mathrm{kg} / \mathrm{s}$ & - & 1606.0 & 1606.0 & 1803.0 & 1689.0 \\
\hline Intermediate pressure & $\mathrm{MPa}$ & 0.51 & - & 1.28 & - & - \\
\hline $\begin{array}{l}\text { Intermediate steam } \\
\text { temperature }\end{array}$ & ${ }^{\circ} \mathrm{C}$ & 260.0 & - & 620.0 & - & - \\
\hline Steam flow after reheating & $\mathrm{kg} / \mathrm{s}$ & 1003.3 & - & 1451.0 & - & - \\
\hline Gas consumption & $\mathrm{kg} / \mathrm{s}$ & - & 30.7 & 43.22 & - & 29.39 \\
\hline Hydrogen consumption & $\mathrm{kg} / \mathrm{s}$ & - & - & - & 21.85 & 9.17 \\
\hline $\begin{array}{l}\text { Additional steam flow after } \\
\text { hydrogen combustion } \\
\text { chamber }\end{array}$ & $\mathrm{kg} / \mathrm{s}$ & - & - & - & 196.67 & 82.56 \\
\hline Feed water temperature & ${ }^{\circ} \mathrm{C}$ & 220.0 & 220.0 & 220.0 & 220.0 & 220.0 \\
\hline Pressure in the condenser & $\mathrm{kPa}$ & 4.9 & 4.9 & 4.9 & 4.9 & 4.9 \\
\hline $\begin{array}{l}\text { Turbo installation power } \\
\text { capacity }\end{array}$ & MW & 1000 & 1735 & 2050 & 2706 & 2503 \\
\hline Additional power capacity & MW & - & 735 & 1050 & 1706 & 1503 \\
\hline Reactor heat power & MW & 2951.0 & 2951.0 & 2951.0 & 2951.0 & 2951.0 \\
\hline $\begin{array}{l}\text { Heat power of outer steam } \\
\text { superheater }\end{array}$ & MW & - & 1438.0 & 2053.0 & 2625.0 & 2472.0 \\
\hline $\begin{array}{l}\text { Turbo installation electrical } \\
\text { efficiency }\end{array}$ & $\%$ & 34.35 & 39.73 & 40.97 & 49.0 & 45.88 \\
\hline $\begin{array}{l}\text { Efficiency of additional } \\
\text { power generation }\end{array}$ & $\%$ & - & 51.12 & 51.15 & 65.0 & 60.78 \\
\hline
\end{tabular}

1 - Thermal scheme of K-1000-5.9/50.

2 - Thermal scheme with single steam superheating up to $600^{\circ} \mathrm{C}$.

3 - Thermal scheme with superheating up to $600^{\circ} \mathrm{C}$ and intermediate reheating up to $620^{\circ} \mathrm{C}$.

4 - Thermal scheme with superheating up to $860^{\circ} \mathrm{C}$.

5 - Scheme with steam superheating up $600^{\circ} \mathrm{C}$ in boiler-superheater with further superheating up to $860^{\circ} \mathrm{C}$ in hydrogen combustion chamber. 


\section{Acknowledgements}

This work was carried out as a part of the Federal Targeted Programme for R \& D in Priority Fields for the Development of Russia's S \& T Complex for 2014-2020, supported by the Ministry of Education and Science of the Russian Federation.

\section{References}

[1] Troyanovskiy, B.M., Filippov, G.A. \& Bulkin, A.E. Steam and gas turbines for nuclear power plants, Moscow: Energoatomizdat, 1985.

[2] Bannister, R.L., Newby, R.A. \& Yang, W.C. Development of HydrogenFueled Combustion Turbine Cycle for Power Generation. Transactions of the ASME, 120, pp. 276-283, 1998.

[3] Fedorov, V.A., Milman, O.O., Power efficient continuous power generation with combined application of fossil and hydrogen fuel. Proc. of Int. Forum Hydrogen Technologies for Power Generation: Moscow, pp. 71-75, 2006. 